\title{
Omeprazole versus placebo for acute upper gastrointestinal bleeding: randomised double blind controlled trial
}

\author{
T K Daneshmend, C J Hawkey, M J S Langman, R F A Logan, R G Long, R P Walt
}

\begin{abstract}
Objective-To investigate the possible therapeutic role of omeprazole, a powerful proton pump inhibitor, in unselected patients presenting with upper gastrointestinal bleeding.

Design-Double blind placebo controlled parallel group study. Active treatment was omeprazole $80 \mathrm{mg}$ intravenously immediately, then three doses of $40 \mathrm{mg}$ intravenously at eight hourly intervals, then $40 \mathrm{mg}$ orally at 12 hourly intervals. Treatment was started within 12 hours of admission and given for four days or until surgery, discharge, or death.
\end{abstract}

Setting-The medical wards of University and City Hospitals, Nottingham.

Subjects -1147 consecutive patients aged 18 years or more admitted over $\mathbf{4 0}$ months with acute upper gastrointestinal bleeding.

Main outcome measures-Mortality from all causes; rate of rebleeding, transfusion requirements, and operation rate; effect of treatment on endoscopic appearances at initial endoscopy.

Results - Of 1147 patients included in the intention to treat analysis, $\mathbf{5 6 9}$ received placebo and 578 omeprazole. No significant differences were found between the placebo and omeprazole groups for rates of transfusion (302 $(53 \%)$ placebo $v 298(52 \%)$ omeprazole), rebleeding (100 (18\%) v $85(15 \%)$ ), operation $(63(11 \%) v 62(11 \%))$, and death $(30(5 \cdot 3 \%)$ $v 40(6.9 \%))$. However, there was an unexpected but significant reduction in endoscopic signs of upper gastrointestinal bleeding in patients treated with omeprazole compared with those treated with placebo (236 (45\%) placebo $v 176(33 \%)$ omeprazole; $\mathbf{p}<\mathbf{0 . 0 0 0 1 )}$.

Conclusions-Omeprazole failed to reduce mortality, rebleeding, or transfusion requirements, although the reduction in endoscopic signs of bleeding suggests that inhibition of acid may be capable of influencing intragastric bleeding. Our data do not justify the routine use of acid inhibiting drugs in the management of haematemesis and melaena.

\section{Introduction}

Acute upper gastrointestinal bleeding continues to be an important reason for admission to hospital. Up to $20 \%$ of patients require surgery and $10 \%$ may die. ${ }^{1.13}$ Trials of medical treatments aimed at reducing mortality and morbidity from upper gastrointestinal bleeding have been largely unrewarding. Large trials have shown no clear reduction in reducing all cause mortality with various ulcer healing drugs including histamine $\mathrm{H}_{2}$ receptor antagonists, ${ }^{45}$ fibrinolytic inhibitors such as tranexamic acid, ${ }^{4}$ and drugs with known actions at multiple sites in the gastrointestinal tract such as somatostatin. ${ }^{12}$ However, meta-analyses of data from published trials have suggested that histamine $\mathrm{H}_{2}$ receptor antagonists ${ }^{8}$ and fibrinolytic inhibitors ${ }^{11}$ may confer therapeutic benefit. Histamine $\mathrm{H}_{2}$ receptor antagonists seem to reduce rates of rebleeding, operation, and death by about $10 \%, 20 \%$, and $30 \%$ respectively ${ }^{8}$ These observations suggest that inhibition of gastric acid secretion may be capable of influencing outcome. We therefore examined the hypothesis that profound suppression of gastric acid secretion with the proton pump inhibitor omeprazole decreases morbidity and mortality from acute upper gastrointestinal bleeding.

Omeprazole is the first available benzimidazole proton pump inhibitor with the capacity effectively to abolish acid secretion. ${ }^{14}$ We have shown that a regimen of high dose intravenous omeprazole causes a rapid and profound inhibition of acid secretion. ${ }^{15}$ We report the results of a randomised double blind placebo controlled clinical trial of its effectiveness in patients presenting with haematemesis or melaena.

\section{Patients and methods}

We examined the death, rebleeding, and operation rates and transfusion requirements in patients admitted to University and City Hospitals, Nottingham, with upper gastrointestinal bleeding between May 1986 and November 1989. Rebleeding was defined as overt haematemesis; passage of fresh blood from the rectum; a fall in haemoglobin concentration of more than $20 \mathrm{~g} / \mathrm{l}$ within any 24 hour period after the first 24 hours; shock in the presence of continuing melaena; or the presence of fresh blood in the stomach or duodenum, or both, at repeat endoscopy when further bleeding was suspected.

All patients with overt upper gastrointestinal bleeding or a history of haematemesis or melaena, or both, within 24 hours preceding admission were eligible for entry into the study provided they did not meet any of the exclusion criteria. These criteria were age below 18 years; pregnant; the presence of severe physical illness making active treatment according to the protocol inappropriate (for example, terminal disease or advanced malignancy); bleeding of such severity that immediate surgery was indicated; trivial bleeding such that active management was unnecessary; bleeding developing in patients who had been admitted to hospital for other reasons; previous participation in the study; inability to start treatment within 12 hours of admission; and potential for drug interactions-for example patients taking phenytoin and warfarin. Ethical approval was obtained from the Nottingham hospitals ethics committees. Wherever possible eligible patients gave verbal consent to inclusion in this study and patients who were unwilling to participate were not enrolled. Consent was not sought from patients who were too unwell to understand the study's aims.

\section{TREATMENT}

Each treatment pack contained four intravenous 
doses and six oral doses of omeprazole or matching placebo. The treatments were randomised in blocks of 10. The intravenous formulation was supplied as a freeze dried compound and solvent in a twin pack vial and ampoule combination. Immediately before use 10 $\mathrm{ml}$ of the solvent $(40 \%$ polyethylene glycol 400 and phosphate buffer in water) was added to the freezedried compound and thoroughly mixed. The intravenous placebo was mannitol, which appears identical to freeze-dried omeprazole and was given in an identical fashion. Injections were given over five minutes. Oral omeprazole $40 \mathrm{mg}$ was given as two hard gelatin capsules each containing $20 \mathrm{mg}$ as enteric coated granules. The oral placebo was identical in appearance.

The trial was double blind. Patients were considered for entry immediately after admission to hospital and were given trial treatment without endoscopic confirmation of bleeding or its site. Each patient was given omeprazole $80 \mathrm{mg}$ or placebo intravenously as soon as possible after admission. A second intravenous dose of omeprazole $40 \mathrm{mg}$ or placebo was given between four and 11 hours later. The interval was varied in order to synchronise subsequent dosing schedules. Two further intravenous doses of omeprazole $40 \mathrm{mg}$ or placebo were given at eight hourly intervals, followed by six oral doses of omeprazole $40 \mathrm{mg}$ or placebo given at 12 hourly intervals over three days. Treatment was continued (whether or not rebleeding occurred) for up to 101 hours or until operation, death, or discharge. Thereafter subsequent treatment was at the discretion of the managing physician

\section{ENDOSCOPY AND CLINICAL MANAGEMENT}

Endoscopy was generally performed within 24 hours of admission, but gastroenterologists at both hospitals were available on a 24 hour basis for earlier endoscopy in patients whose clinical condition required it. Endoscopists were asked to record the presence or absence of signs predictive of rebleeding: blood in the stomach red clot on lesion, active bleeding, black spots on lesion, visible vessel. Endoscopic treatment of bleeding such as injection of varices was allowed at the discretion of the endoscopist.

Patients were cared for by the admitting medical team, who made decisions about clinical management, blood transfusion, and surgery. Patients were managed in general medical wards or in a high dependency unit, depending on the severity of bleeding. Gastroenterologists in both hospitals were available for advice but did not enter into the primary management of patients other than those initially admitted under their care. Concurrent treatment with histamine $\mathrm{H}_{2}$ receptor antagonists, bismuth chelate, carbenoxolone, or sucralfate was not allowed but on completion of the study treatment further drugs could be given at the discretion of the supervising physician. Non-steroidal antiinflammatory drugs and aspirin were stopped on admission to hospital.

\section{CRITERIA FOR STOPPING TREATMENT}

Trial treatment was stopped and the patient withdrawn if the patient was considered not to have had upper gastrointestinal bleeding; severe medical problems developed that necessitated breaking the treatment code; the patient was unwilling to continue in the study; or there was non-compliance with the study protocol. Interim analyses of overall mortality, based on the O'Brien and Fleming procedure for group sequential tests, ${ }^{16}$ were performed by an independent statistician after 200 and 500 patients had completed the trial in order to screen for unsuspected hazards associated with omeprazole.

REVIEW OF DEATHS

A final diagnosis was assigned to each patient at death or discharge on the basis of details available in the clinical record form. In addition, the hospital records and necropsy reports of all patients who had died during the trial were reviewed by RFAL and $\mathrm{CJH}$ to confirm the cause of upper gastrointestinal bleeding and assess the contribution bleeding had made to death. This review was carried out before the randomisation code was broken. Deaths were categorised as follows. (1) Upper gastrointestinal bleeding was the direct cause of death, as shown by continued melaena, haematemesis, fall in haemoglobin concentration, etc, and including cardiac arrest when haemoglobin $<80$ g/l. (2) Upper gastrointestinal bleeding caused hospital admission but subsequently had stopped or become trivial. Death from medical complications (for example, pneumonia). (3) Death after surgery had controlled bleeding. (4) Death during or after surgery which had not controlled bleeding. (5) Upper gastrointestinal bleeding was incidental to the condition leading to death (for example, death from stroke secondary to pre-existing thrombocytopenia). (6) Significant upper gastrointestinal bleeding never shown - normal appearance on endoscopy and no fall in haemoglobin concentration. This included deaths where bleeding was shown to arise from beyond the duodenum. Some of these patients were classified as "other" or "cause unclear" in the primary endoscopic diagnosis and whose final diagnosis was based on review of case records. (7) Death where gastroduodenal perforation followed bleeding. (8) Otherscauses of death not classified above (for example, carcinoma of pancreas).

Deaths were categorised according to whether the cause of bleeding was from duodenal ulceration, gastric ulceration, gastric erosions, oesophageal ulceration or oesophagitis, gastric cancer, oesophageal varices, abnormalities distal to the descending duodenum, and other or unknown causes.

\section{STATISTICAL ANALYSIS}

All study variables were analysed according to intention to treat. Main variables were also analysed by the per protocol approach, in which patients violating the protocol regulations were excluded. All decisions on exclusion of patients from analysis were taken before breaking the treatment code.

Mortality in all patients and in the subgroup of patients with confirmed upper gastrointestinal bleeding and in those with gastric and duodenal ulcers was analysed. The associations between trial treatment, treatment centre, age $(\leqslant 54,55-64,>64$ years), initial systolic blood pressure $(\leqslant 100,>100 \mathrm{~mm} \mathrm{Hg})$, and bleeding site (gastric ulcer, duodenal ulcer, other) and rebleeding, operation, and death were examined.

The proportion of patients with each outcome (death, operation, etc) was analysed with the MantelHaenszel test stratified by centre. ${ }^{17}$ Continuous variables were tested by Wilcoxon tests stratified by centre. Confidence intervals for proportions were calculated by using the standard normal approximation. The effect of possible prognostic factors on binary variables (mortality, operation, and rebleeding) was analysed by logistic regression models. ${ }^{17}$ The sample size $(1100$ patients) was based on an assumption of a reduction of mortality from all causes by omeprazole from $10 \%$ to $5 \%\left(\alpha=0.05,1-\beta=0.8\right.$, two tailed significance). ${ }^{18}$

\section{Results}

We randomised 1154 patients into the study. Four of these patients were not given the study treatment (one omeprazole group, three placebo group) and in three the treatment given could not subsequently be clearly identified. The remaining 1147 patients were successfully randomised to receive omeprazole $(n=578)$ 
or placebo $(n=569)$. Of these, 698 patients were admitted to University Hospital and 449 to City Hospital. Table I shows that the treatment groups were well matched for possible prognostic features. Most (1063) patients were examined by endoscopy; 937 were examined within the first 24 hours. The commonest reason for endoscopy not being performed was the need for urgent surgery. The groups were well matched for time of endoscopy and for amount of treatment received. There were 98 protocol violations $(62$ patients were prescribed concomitant $\mathrm{H}_{2}$ antagonists, 18

TABLE I-Demographic details of patients randomised to receive placebo or omeprazole for upper gastrointestinal bleeding

\begin{tabular}{lcc}
\hline & $\begin{array}{c}\text { Placebo } \\
\text { group }\end{array}$ & $\begin{array}{c}\text { Omeprazole } \\
\text { group }\end{array}$ \\
\hline No of patients & 569 & 578 \\
M/F & $354 / 215$ & $375 / 203$ \\
Mean (SD) age & $59(19)$ & $60(19)$ \\
Mean (SD) systolic blood pressure & $129(26)$ & $127(25)$ \\
Mean (SD) pulse & $90(16)$ & $91(16)$ \\
Mean (SD) haemoglobin & $11(3)$ & $11(3)$ \\
No(\%) with haemoglobin <100 g/l & $188(33)$ & $192(33)$ \\
No(\%) with: & $395(69)$ & $402(70)$ \\
Haematemesis & $324(57)$ & $309(53)$ \\
Melaena & $146(26)$ & $152(26)$ \\
Previous peptic ulcer & $117(21)$ & $135(23)$ \\
Previous upper gastrointestinal bleeding & $37(7)$ & $35(6)$ \\
Previous gastric surgery & $16(3)$ & $21(4)$ \\
No(\%) given endoscopic treatment & $243(43)$ & $233(40)$ \\
No(\%) aged (years): & $197(35)$ & $191(33)$ \\
$\quad<60$ & $129(23)$ & $154(27)$ \\
60-74 & & \\
$\geqslant 75$ & &
\end{tabular}

TABLE II - Primary endoscopic and final diagnoses by treatment group. Figures are numbers (percentages) of patients

\begin{tabular}{|c|c|c|c|c|}
\hline & \multicolumn{2}{|c|}{ Initial diagnosis } & \multicolumn{2}{|c|}{ Final diagnosis } \\
\hline & $\begin{array}{c}\text { Placebo } \\
\text { group } \\
(\mathbf{n}=569)\end{array}$ & $\begin{array}{c}\text { Omeprazole } \\
\text { group } \\
(\mathbf{n}=578)\end{array}$ & $\begin{array}{c}\text { Placebo } \\
\text { group } \\
(\mathbf{n}=569)\end{array}$ & $\begin{array}{c}\text { Omeprazole } \\
\text { group } \\
(\mathbf{n}=578)\end{array}$ \\
\hline Ulcers & $262(46)$ & $250(43)$ & $280(49)$ & $274(47)$ \\
\hline Oesophageal & $23(4)$ & $31(5)$ & $23(4)$ & $28(5)$ \\
\hline Gastric & $85(15)$ & $87(15)$ & $93(16)$ & $97(17)$ \\
\hline Duodenal & $154(27)$ & $132(23)$ & $164(29)$ & $149(26)$ \\
\hline Erosive disease & $102(18)$ & $123(21)$ & $99(17)$ & $120(21)$ \\
\hline Oesophagitis or hiatus hernia & $51(9)$ & $66(11)$ & $49(9)$ & $62(11)$ \\
\hline Gastritis & $43(8)$ & $40(7)$ & $42(7)$ & $40(7)$ \\
\hline Duodenitis & $8(1)$ & $17(3)$ & $8(7)$ & $18(3)$ \\
\hline Mallory-Weiss tears & $17(3)$ & $18(1)$ & $20(4)$ & $19(3)$ \\
\hline Oesophageal varices & $16(3)$ & $12(2)$ & $16(3)$ & $13(2)$ \\
\hline Carcinoma of stomach & $1(<1)$ & $6(1)$ & $7(1)$ & $11(2)$ \\
\hline Leiomyoma & $1(<1)$ & $2(<1)$ & $1(<1)$ & $2(<1)$ \\
\hline Vascular lesion & & $1(<1)$ & & $1(<1)$ \\
\hline Normal/no bleed/cause unclear & $104(18)$ & $99(17)$ & $108(19)$ & $99(17)$ \\
\hline Other & $22(4)$ & $23(4)$ & $38(7)$ & $39(7)$ \\
\hline Endoscopy not done ${ }^{\star}$ & $44(8)$ & $44(8)$ & & \\
\hline
\end{tabular}

^For most patients in whom endoscopy was not done the final diagnosis was based on clinical and operativ information available at the time of discharge or death.

TABLE III-Clinical outcomes in patients with upper gastrointestinal bleeding. Figures are numbers (percentages) of patients unless stated otherwise

\begin{tabular}{|c|c|c|c|c|}
\hline & \multicolumn{2}{|c|}{ Intention to treat analysis } & \multicolumn{2}{|c|}{ Per protocol analysis } \\
\hline & $\begin{array}{l}\text { Placebo } \\
\text { group } \\
(\mathrm{n}=569)\end{array}$ & $\begin{array}{c}\text { Omeprazole } \\
\text { group } \\
(\mathbf{n}=578)\end{array}$ & $\begin{array}{l}\text { Placebo } \\
\text { group } \\
(\mathrm{n}=529)\end{array}$ & $\begin{array}{c}\text { Omeprazole } \\
\text { group } \\
(\mathbf{n}=520)\end{array}$ \\
\hline Rebleeding & $100(18)$ & $85(15)$ & $91(17)$ & $77(15)$ \\
\hline Transfusion & $302(53)$ & $298(52)$ & $279(53)$ & $263(51)$ \\
\hline Transfusion of $\geqslant 3$ units of blood & $237(42)$ & $226(39)$ & $217(41)$ & $202(39)$ \\
\hline Operation & $63(11)$ & $62(11)$ & 57 (11) & $56(11)$ \\
\hline Median time to discharge (days) & 6 & 5 & 6 & \\
\hline Death & $30(5 \cdot 3)$ & $40(6 \cdot 9)$ & $29(5 \cdot 5)$ & $35(6 \cdot 7)$ \\
\hline $\begin{array}{r}\text { Difference ( } 95 \% \text { confidence interval) } \\
\text { in death rate (omeprazole-placebo) }\end{array}$ & \multicolumn{2}{|c|}{$1.6 \%(-1 \cdot 2 \%$ to $4 \cdot 4 \%)$} & \multicolumn{2}{|c|}{$1 \cdot 2 \%(-1 \cdot 7 \%$ to $4 \cdot 1 \%)$} \\
\hline
\end{tabular}

TABLE IV-Number (percentage) of patients with peptic ulcers with various clinical outcomes

\begin{tabular}{|c|c|c|c|c|}
\hline & \multicolumn{2}{|c|}{ Gastric ulcer } & \multicolumn{2}{|c|}{ Duodenal ulcer } \\
\hline & $\begin{array}{l}\text { Placebo } \\
\text { group } \\
(\mathbf{n}=93)\end{array}$ & $\begin{array}{l}\text { Omeprazole } \\
\text { group } \\
(\mathbf{n}=97)\end{array}$ & $\begin{array}{l}\text { Placebo } \\
\text { group } \\
(\mathrm{n}=164)\end{array}$ & $\begin{array}{c}\text { Omeprazole } \\
\text { group } \\
(\mathrm{n}=149)\end{array}$ \\
\hline Rebleeding & $23(25)$ & $26(27)$ & $47(29)$ & $32(21)$ \\
\hline Operation & $16(17)$ & $18(19)$ & $34(21)$ & 27 (18) \\
\hline Death & $5(5)$ & $7(7)$ & $8(5)$ & $16(11)$ \\
\hline
\end{tabular}

entered the trial for a second time, 15 started treatment more than 12 hours after admission, and three were under age or possibly pregnant) leaving 529 on placebo and 520 on omeprazole available for per protocol analysis. Table II shows the primary endoscopic and final diagnoses: the distribution of disease randomised to each treatment was similar.

CLINICAL OUTCOME

Table III shows the outcome in patients analysed by intention to treat. Patients receiving omeprazole had slightly lower transfusion requirements and rebleeding rates than control patients, but these differences were not significant. Moreover, the death rate was slightly higher in patients who received omeprazole $(6 \cdot 9 \%)$ compared with those treated with placebo $(5 \cdot 3 \%)$, though the difference was not significant.

Table III also shows the outcome in 1049 patients included in the per protocol analysis. Results in these patients were similar to those obtained in the intention to treat analysis. Results in the 945 patients with confirmed upper gastrointestinal bleeding (477 omeprazole, 468 placebo) also showed a similar pattern of results. In this group $29(6 \cdot 1 \% ; 95 \%$ confidence interval $4.0 \%$ to $8 \cdot 2 \%$ ) of those who received omeprazole and $23(4.9 \% ; 2.9 \%$ to $6.9 \%)$ of those who received placebo died (NS). Table IV shows that the pattern of results in patients with peptic ulcers was.also generally similar to that seen in the group as a whole. There was an excess of deaths in patients with duodenal ulcer treated with omeprazole rather than placebo (16v eight), but this difference was not significant. A total of 155 patients (73 omeprazole group, 82 placebo group) was taking aspirin or non-aspirin non-steroidal antiinflammatory drugs. Of these, 91 had ulcers (41 omeprazole group, 50 placebo group). Sixteen (10\%) of the 155 patients died (nine in omeprazole group, seven in placebo group). All but two of the patients taking non-steroidal anti-inflammatory drugs who died had peptic ulcers. Of patients with oesophageal varices, three who received omeprazole and three who received placebo died. Thirty nine patients received endoscopic treatment (15 in omeprazole group, 17 in placebo group); treatment was of variceal sclerotherapy (20 patients) or treatment of ulcer bleeding by diathermy, heater probe, or sclerotherapy ( 11 with duodenal ulcer, four with gastric ulcer). Five of the patients who received endoscopic treatment died (three in omeprazole group, two in placebo group).

\section{ADJUSTMENT FOR AGE AND OTHER PROGNOSTIC FACTORS}

The group treated with omeprazole were slightly older than the placebo treated group (table I) Standardising the mortality according to the bands in table I resulted in a small reduction in mortality in the omeprazole group to $6.7 \%$ (95\% confidence interval $4.6 \%$ to $8.8 \%$ ) with no change in the placebo group at $5 \cdot 3 \%(3 \cdot 4 \%$ to $7 \cdot 3 \%)$.

Logistic regression was used to analyse the combined effects of age, initial systolic blood pressure, bleeding site, centre, and treatment group on rates of rebleeding, operation, and death. For all three outcomes increasing age $(\mathrm{p}<0.0001)$ and a low initial systolic blood pressure $(p<0.001)$ were the strongest prognostic factors. The presence of a gastric or duodenal ulcer was a significant factor for rebleeding $(p<0.01)$ and operation $(p<0.005)$ but not for death $(p=0 \cdot 12)$. The treatment centre was unrelated to all three outcomes. Relations between treatment groups and rebleeding $(p=0 \cdot 10)$, operation $(p=0.64)$, or mortality $(p=0 \cdot 33)$ were not significant.

\section{RESULT OF ENDOSCOPY}

In contrast with the results concerning rates of rebleeding, operation, and death, treatment with 
omeprazole was associated with a highly significant reduction in the incidence of endoscopic signs of bleeding (table V). Patients who received omeprazole had lower rates of blood in the stomach, active bleeding, red clot on the lesion, and black spots on the lesion than patients receiving placebo.

TABLE $\mathrm{v}-$ Number (percentage) of patients with signs of bleeding on endoscopy

\begin{tabular}{lccc}
\hline & $\begin{array}{c}\text { Placebo group } \\
(\mathbf{n}=525)\end{array}$ & $\begin{array}{c}\text { Omeprazole group } \\
(\mathbf{n}=534)\end{array}$ & $\mathrm{p}$ Value \\
\hline Any sign & $236(45)$ & $176(33)$ & $<0 \cdot 0001$ \\
Blood in stomach & $131(25)$ & $107(20)$ & \\
Red clot on lesion & $115(22)$ & $85(16)$ & \\
Active bleeding & $73(14)$ & $53(10)$ & \\
Black spots on lesion & $58(11)$ & $39(7)$ & \\
Visible vessel & $16(3)$ & $22(4)$ & \\
\hline
\end{tabular}

Some patients had more than one sign.

\section{POSTOPERATIVE AND LATE DEATHS}

On an intention to treat basis 20 of the 40 patients treated with omeprazole who died did so after surgery compared with six of 30 patients given placebo (table VI). The difference in postoperative death rates ( 20 out of 62 patients given omeprazole who had operations versus six out of 63 patients given placebo) was significant $(p=0 \cdot 004)$. Twelve patients treated with omeprazole died after surgical control of bleeding compared with four who received placebo. This included nine who received omeprazole and four who received placebo with bleeding from ulcers, erosions, or oesophagitis. Nine of the patients in the omeprazole group who died had cancer (four gastric, four colonic, one cervix) compared with only two in the placebo group (one gastric, one colonic). Lower gastrointestinal bleeding accounted for five deaths in the omeprazole group versus none in the placebo group. Recipients of omeprazole also seemed to have had somewhat more complex operations; 14 patients had gastrectomies (versus eight in placebo group) and five had colectomies (versus none in placebo group). These differences probably explain the larger number of patients in the omeprazole group (24 versus 11 in placebo group) who died on or after day 6 of admission (figure).

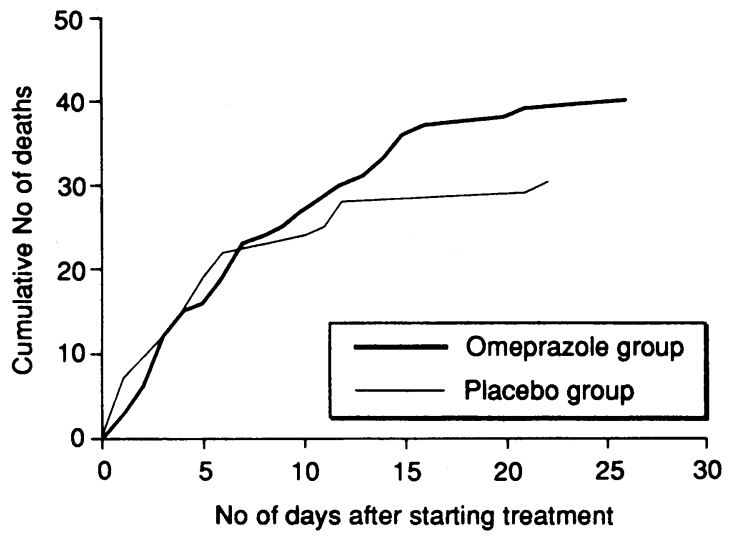

There was no evidence of any toxic effect of omeprazole in the form of altered liver function, unexpected hepatic or renal failure, or sudden unexpected death, and careful review showed no particular pattern of events preceding death in the omeprazole group. No individual anaesthetic drug was associated with the excess mortality in the omeprazole group.

\section{Discussion}

We found no reduction in mortality in unselected patients presenting with upper gastrointestinal bleeding who were given omeprazole. There were no significant differences in the rates of rebleeding or operation or transfusion requirements between the two groups. However, the overall death rate of $6 \%$ was nearly half that expected. Confidence intervals were consistent with the possibility of a real but undetected benefit as well as possible harm caused by treatment. Moreover, patients treated with omeprazole were by chance more likely to die postoperatively, to have cancer, or to be bleeding from the lower gut than those treated with placebo.

Treatment with omeprazole was associated with a significant reduction in active bleeding and other signs evident at endoscopy. This was unexpected as changes in endoscopic signs had not been seen in patients given active treatment in previous studies in Nottingham. ${ }^{410}$ For example, in a similarly designed study of cimetidine and tranexamic acid $25 \%$ of patients receiving placebo, $26 \%$ of those receiving cimetidine, and $29 \%$ of those receiving tranexamic acid had blood in the stomach at endoscopy. ${ }^{4}$ In the present study the rate for active bleeding in the placebo group $(25 \cdot 1 \%)$ was very similar, suggesting that the patient cohort was similar to those we have previously studied. Changes in endoscopic signs were not selected as an end point before the trial and reduction in such signs could be a chance finding. Nevertheless, the probability that a reduction of this size would be observed by chance is less than one in 10000 , making it likely that the reduction was a consequence of drug treatment. In preliminary dose ranging studies before starting this study we showed that the regimen chosen for the study increased median $\mathrm{pH}$ to $>4$ within 1 hour in patients with duodenal ulcers, ${ }^{15}$ so a reduction in endoscopic signs of bleeding is plausible.

As in previous studies, ${ }^{19-21}$ patients with signs of recent haemorrhage were more likely to have rebleeding than those without, and this was seen in both treatment groups. Despite early reductions in signs of bleeding with omeprazole mortality was not reduced. This raises the possibility that the high doses of omeprazole that we were using might be toxic and obscure a beneficial effect of omeprazole on mortality. Since the excess of deaths in the omeprazole group occurred in postoperative patients, an interaction with anaesthetic drugs, leading to hepatic or renal failure might account for the deaths, but we found no evidence of this. In patients in intensive care units raised intragastric $\mathrm{pH}$ has been reported to be associ- patients with upper gastrointestinal bleeding treated with placebo and omeprazole

TABLE VI - Cause of upper gastrointestinal bleeding and role in patients' death after review

\begin{tabular}{|c|c|c|c|c|c|c|c|c|c|c|c|c|}
\hline \multirow{2}{*}{$\begin{array}{l}\text { Role of bleeding in death } \\
\text { (review categories) }\end{array}$} & \multicolumn{2}{|c|}{$\begin{array}{l}\text { Duodenal ulcer, gastric } \\
\text { ulcer, erosions, and } \\
\text { oesophagitis }\end{array}$} & \multicolumn{2}{|c|}{ Gastric cancer } & \multicolumn{2}{|c|}{ Varices } & \multicolumn{2}{|c|}{$\begin{array}{c}\text { Cause not known/bleeding } \\
\text { not confirmed }\end{array}$} & \multicolumn{2}{|c|}{ All patients } & \multicolumn{2}{|c|}{ Postoperative deaths } \\
\hline & Placebo & Omeprazole & Placebo & Omeprazole & Placebo & Omeprazole & Placebo & Omeprazole & Placebo & Omeprazole & Placebo & Omeprazole \\
\hline Continued bleeding $(1,4)$ & 8 & 7 & 1 & 1 & 3 & 3 & 0 & 0 & 12 & 11 & 1 & 2 \\
\hline Medical complications (2) & 3 & 4 & 0 & 0 & 0 & 0 & 2 & 2 & 5 & 6 & 1 & $0^{\star}$ \\
\hline $\begin{array}{l}\text { Died after surgery had } \\
\text { controlled bleeding (3) }\end{array}$ & 4 & 9 & 0 & 2 & 0 & 0 & 0 & 1 & 4 & 12 & 4 & 12 \\
\hline $\begin{array}{l}\text { Bleeding incidental or not } \\
\text { demonstrated }(5,6,7,8)\end{array}$ & 4 & 3 & 0 & 1 & 0 & 0 & 5 & 7 & 9 & 11 & 0 & 6 \\
\hline Total & 19 & 23 & 1 & 4 & 3 & 3 & 7 & 10 & 30 & 40 & 6 & 20 \\
\hline
\end{tabular}

$\star$ One patient died after laparotomy for mesenteric embolus after stopping warfarin because of a bleeding gastric ulcer. 
ated with the development of pneumonia. ${ }^{22}{ }^{23}$ Review of the notes of patients who died showed no evidence suggesting an excess of pneumonia in patients taking omeprazole, although this may have been missed as the study was not specifically designed to detect this.

\section{DIFFERENCES BETWEEN OMEPRAZOLE AND}

PLACEBO GROUPS

In theory improved endoscopic appearances in patients receiving omeprazole might delay operation, and this could explain the apparent increase in postoperative deaths of patients with ulcers, erosions, or oesophagitis. However, there was no difference in the timing of operation in these patients. Much of the increased postoperative mortality in patients taking omeprazole was attributable to more patients dying of cancer or lower gastrointestinal bleeding-diagnoses not likely to be affected by treatments aimed at elevating intragastric $\mathrm{pH}$. Some of these patients had "open and shut" laparotomies, whereas others had delayed operations for lower gastrointestinal lesions, which nevertheless caused death within the 40 days of our study protocol. It seems more likely that the excess postoperative deaths in these patients occurred by chance rather than as a result of a (theoretical and unspecified) harmful effect of omeprazole on patients with cancer or lower gastrointestinal lesions. Patients on omeprazole also tended to have more complex operations than those receiving placebo, which could have affected later outcome. It is equally difficult to decide whether the increased proportion of deaths in patients with duodenal ulcer who received omeprazole has implications. We have seen similar trends in previous studies using other drugs ${ }^{4}{ }^{10}$ so the possibility that acid suppression is harmful in one specific subgroup of patients may deserve further investigation.

Our study illustrates some of the problems of investigating treatments intended to reduce the mortality from haematemesis and melaena. As well as the differences between the two groups in the causes of death, the study lacked the statistical power that was intended. Despite an aging population with a pattern of underlying disease and severity of bleeding comparable with that seen in our previous studies, ${ }^{410}$ the mortality from haematemesis and melaena was significantly lower than in our earlier studies. This means that, despite being the largest trial of treatment of upper gastrointestinal bleeding reported, it was still too small to detect changes in mortality of clinical relevance. The confidence intervals for the effect of omeprazole could still be compatible with a $30 \%$ reduction in death rate. Such a reduction would be of clinical interest, but to detect a reduction in mortality from $6 \%$ to $4 \%$ with $80 \%$ power a trial of over 4200 patients would be required. The fall in mortality seen in our patients is similar to changes attributed by others to the use of purpose built units with dedicated teams. ${ }^{262425}$ Our data suggest that background changes, such as possible improved fitness of elderly patients, ${ }^{26}$ may be more important.

The administration of acid inhibiting drugs to patients with haematemesis and melaena remains widespread despite a lack of evidence for their value. Our failure to show a beneficial effect on clinically important end points with an inhibitor as potent as omeprazole is further evidence that this practice is unjustified. The interesting observation that omeprazole is associated with reductions in endoscopic signs of bleeding warrants further investigation but does not support the use of acid inhibition since there is no evidence yet that a reduction in endoscopic stigmata is of clinical benefit.

This study was supported by a grant from Astra Clinical Research. We are pleased to acknowledge the role of colleagues in enrolling patients and the help of Astra in analysis.

1 Allan R, Dykes P. A study of the factors influencing mortality rates from gastrointestinal haemorrhage. $Q \mathcal{F}$.Med 1976;45:533-50.

2 Hunt PS, Hansky J, Korman MG. Mortality in patients with haematemesis and melaena; a prospective study. BMf 1979; i: 1239-40.

3 Silverstein FE, Gilbert DA, Tedesco FJ, Buenger NK, Persing J. The national ASGE survey on upper gastrointestinal bleeding. II. Clinical prognostic features. Gastrointest Endosc 1981;27:80-93.

4 Barer D, Ogilvie A, Henry D, Dronfield M, Coggon D, French S, et al. Cimetidine and tranexamic acid in the treatment of acute upper gastroCimetidine and tranexamic acid in the treatment
intestinal bleeding. N Engl f Med 1983;308:1571-5.

5 Walt RP, Cottrell J, Mann SG, Freemantle N, Langman MJSL. Randomised, double blind, controlled trial of intravenous famotidine infusion in 1005 double blind, controlled trial of intravenous famotidine
patients with peptic ulcer bleeding. Gut 1991;32:A571-2.

6 Fleischer D. Etiology and prevalence of severe persistent upper gastrointestinal bleeding. Gastioenterology 1983;84:539-43.

7 Morris DL, Hawker PC, Brearly S, Simms M, Dykes PW, Keighley MRB Optimal timing of operation for bleeding peptic ulcer: prospective random ised trial. BMF 1984;288:1277-80.

8 Collins R, Langman M. Treatment with histamine $\mathrm{H}_{2}$ antagonists in acute upper gastrointestinal haemorrhage. Implications or randomised trials. NEnglf Med 1985;331:660-6.

9 Bordley DR, Mushlin AI, Dolan JG, Richardson WS, Barry M, Polio J. Early clinical signs identify low risk patients with acute upper gastrointestinal haemorrhage. FAMA 1985;253:3282-5.

10 Somerville KW, Henry DA, Davies JG, Hine KR, Hawkey CJ, Langman MJS. Somatostatin in treatment of haematemesis and melaena. Lancet 1985;i:130-2.

11 Henry DA, O'Connell DL. Effects of fibrinolytic inhibitors on mortality from upper gastrointestinal haemorrhage. BMJ 1989;298:1142-6.

12 Christiansen J, Ottenjann R, Arx FV. Placebo-controlled trial with the somatostatin analogue SMS 201-995 in peptic ulcer bleeding. Gastroenterology 1989;97:568-74.

13 Peterson WL. Pharmacotherapy of bleeding peptic ulcer-is it time to give up the search? Gastroenterology 1989;97:796-7.

14 Clissold SP, Campoli-Richards DM. Omeprazole. An updated review. Drugs 1988;34:1-41.

15 Walt RP, Reynolds JR, Langman MJS, Smart HL, Kitchingman G Somerville $\mathrm{KW}$, et al. Intravenous omeprazole rapidly raises intragastric pH. Gut 1985;26:902-6.

16 O'Brien PC, Fleming TR. A multiple testing procedure for clinical trials Biometrics 1979;35:549-56.

17 Kleinbaum DG, Kupper LL, Morgenstern H. Epidemiologic research Belmont, California: Lifetime Learning Publications, 1982:419-75.

18 Fleiss JL. Statistical methods for rates and proportions. 2nd ed. New York: John Wiley and Sons, 1981:173-5.

19 Foster DN, Miloszewski KJA, Losowsky MS. Stigmata of recent haemorrhage in diagnosis and prognosis of upper gastrointestinal bleeding. $B M \mathcal{Y}$ 1978;ii:1173-7.

20 Griffiths WJ, Neumann D, Welsh JD. The visible vessel as an indicator of uncontrolled or recurrent gastrointestinal haemorrhage. $N$ Engl f Med 1979;300:1411-3.

21 Storey DW, Bown SG, Swain PC, Salmon PR, Kirkham JS, Northfield TC. Endoscopic prediction of recurrent bleeding in peptic ulcers. $N$ Engl $7 \mathrm{Med}$ 1981;305:915-6.

22 Driks MR, Craven DE, Celli RC, Manning M, Burke RA, Garvin GM, et al. Nosocomial pneumonia in intubated patients given sucralfate as compared with antacids or histamine type 2 blockers. The role of gastric colonisation. N Englf Med 1987;317:1376-82.

23 Garvey BM, McCambley JA, Tuxen DV. Effects of gastric alkalinisation on bacterial colonisation in critically ill patients. Crit Care Med 1989;17:211-6.

24 Holman RAE, Davis M, Gough KR, Gartell P, Britton DC, Smith RB. Value of a centralised approach in the management of haematemesis and melaena: oxperience in a district general hospital. Gut 1990;31:504-8.

25 Sanderson JD, Foley N, Vicary FR. Optimising patient care in upper gastrointestinal haemorrhage: specialised units are the answer. Gut 1990;31:
and A1206.

26 Jagger $C$, Clarke $M$, Clarke SJ. Getting older - feeling younger: the changing health profile of the elderly. Int $\mathcal{F}$ Epidemiol 1991;20:234-8.

(Accepted 18 October 1991)

\section{Correction}

Risk of epilepsy after febrile convulsions: a national cohort study

Several authors' errors occurred in table II of this paper by $\mathrm{C} \mathrm{M}$ Verity and Jean Golding ( 30 November, p 1373). In the firs column of table II the number of children who had tonic-clonic seizures who had not had febrile convulsions should have been 32 the number of tonic-clonic seizures expected in children who had febrile convulsions should have been 0.9 ; and the number observed/expected should have been 11 . 